\title{
Analogues of Marine Guanidine Alkaloids Are in Vitro Effective against Trypanosoma cruzi and Selectively Eliminate Leishmania (L.) infantum Intracellular Amastigotes
}

Martins, Ligia F.; Mesquita, Juliana T.; Pinto, Erika G.; Costa-Silva, Thais A.; Borborema, Samantha E. T.; Galisteo Junior, Andres J. ; Neves, Bruno J. ; Andrade, Carolina H. ; Bennett, Elliot; Black, Gregory; Harper, Philip; Evans, Daniel; Fituri, Hisham; Leyland, John P.; Martin, Claire; Roberts, Terence; Thornhill, Andrew J.; Vale, Steven; Howard-Jones, Andrew; Thomas, Dafydd; Williams, Harri L.; Overman, Larry; Berlinck, Roberto ; Murphy, Patrick; Tempone, Andre

\section{Journal of natural products}

DOI:

10.1021/acs.jnatprod.6b00256

Published: 16/09/2016

Peer reviewed version

Cyswllt i'r cyhoeddiad / Link to publication

Dyfyniad o'r fersiwn a gyhoeddwyd / Citation for published version (APA):

Martins, L. F., Mesquita, J. T., Pinto, E. G., Costa-Silva, T. A., Borborema, S. E. T., Galisteo Junior, A. J., Neves, B. J., Andrade, C. H., Bennett, E., Black, G., Harper, P., Evans, D., Fituri, H., Leyland, J. P., Martin, C., Roberts, T., Thornhill, A. J., Vale, S., Howard-Jones, A., ...

Tempone, A. (2016). Analogues of Marine Guanidine Alkaloids Are in Vitro Effective against Trypanosoma cruzi and Selectively Eliminate Leishmania (L.) infantum Intracellular Amastigotes. Journal of natural products, 79(9), 2202-2210. https://doi.org/10.1021/acs.jnatprod.6b00256

\footnotetext{
Hawliau Cyffredinol / General rights

Copyright and moral rights for the publications made accessible in the public portal are retained by the authors and/or other copyright owners and it is a condition of accessing publications that users recognise and abide by the legal requirements associated with these rights.

- Users may download and print one copy of any publication from the public portal for the purpose of private study or research.

- You may not further distribute the material or use it for any profit-making activity or commercial gain

- You may freely distribute the URL identifying the publication in the public portal ?
} 


\section{Analogues of marine guanidine alkaloids are in vitro effective against Trypanosoma cruzi and selectively eliminate Leishmania $(L$. infantum intracellular amastigotes}

Ligia F. Martins, ${ }^{\dagger}$ Juliana T. Mesquita, ${ }^{\dagger}$ Erika G. Pinto,${ }^{\dagger, \dagger}$ Thais A. Costa-Silva, ${ }^{\dagger}$ Samanta E. T. Borborema, ${ }^{\dagger}$ Andres J. Galisteo Junior, ${ }^{\ddagger}$ Bruno J. Neves,${ }^{\S}$ Carolina H. Andrade, ${ }^{\S}$ Zainab Al Shuhaib,${ }^{\perp}$ Elliot L. Bennett, ${ }^{\perp}$ Gregory P. Black, ${ }^{\perp}$ Philip M. Harper,${ }^{\perp}$ Hisham S. Fituri, ${ }^{\perp}$ John P. Leyland, ${ }^{\perp}$ Claire Martin,$\perp$ Terence D. Roberts, ${ }^{\perp}$ Andrew J. Thornhill, ${ }^{\perp}$ Stephen A. Vale, ${ }^{\perp}$ Andrew Howard-Jones, ${ }^{\perp}$ Dafydd A. Thomas, ${ }^{\perp}$ Harri L. Williams, ${ }^{\perp}$ Larry E. Overman,,$\|$ Roberto G. S. Berlinck, ${ }^{\nabla}$ Patrick J. Murphy, ${ }^{\perp}$ Andre G. Tempone, ${ }^{\dagger *}$

${ }^{\dagger}$ Centre for Parasitology and Mycology, Instituto Adolfo Lutz, Avenida Dr. Arnaldo, 351, $8^{\circ}$ andar, 01246-000 São Paulo, SP, Brazil.

\#nstituto de Medicina Tropical, Universidade de São Paulo, Avenida Dr. Enéas de Carvalho Aguiar, 470, 05403-000 São Paulo, SP, Brazil.

${ }^{\S}$ LabMol - Laboratory for Molecular Modeling and Drug Design, Faculdade de Farmácia, Universidade Federal de Goiás, Goiânia, Brazil

${ }^{\perp}$ School of Chemistry, Bangor University, Bangor, Gwynedd, Wales, UK LL57 2UW.

"University of California, Irvine, 4042A Frederick Reines Hall, Irvine, CA 92697, USA.

${ }^{\nabla}$ Instituto de Química de São Carlos, Universidade de São Paulo, CP 780, CEP 13560-970, São Carlos, SP, Brazil. 
ABSTRACT: Synthetic analogues of marine sponge guanidine alkaloids showed in vitro antiparasitic activity against Leishmania (L.) infantum and Trypanosoma cruzi. Guanidines 10 and 11 presented the highest selectivity index when tested against Leishmania. The antiparasitic activity of $\mathbf{1 0}$ and $\mathbf{1 1}$ was investigated in host cells and in parasites. Both compounds induced depolarization of mitochondrial membrane potential, upregulation of reactive oxygen species (ROS) levels and increased plasma membrane permeability in Leishmania parasites.

Immunomodulatory assays suggested an NO-independent effect of guanidines $\mathbf{1 0}$ and $\mathbf{1 1}$ on macrophages. The same compounds also promoted anti-inflammatory activity in $L$. (L.) infantuminfected macrophages co-cultived with splenocytes, reducing the production of cytokines MCP-1 and IFN- $\gamma$. Guanidines $\mathbf{1 0}$ and $\mathbf{1 1}$ affect the bioenergetic metabolism of Leishmania, with selective elimination of parasites via a host-independent mechanism. 
Considerable attention has been raised to address the effective cure of neglected tropical diseases (NTDs) in the last decade, which globally impact mainly economically disfavored nations. These infectious pathogenies, of which most have parasites as the causative agents, have spread and now affect population in developed countries as well. Most drugs to treat NTDs were developed decades ago and show harmful, even deadly, adverse effects. Therefore, the search for new drugs or vaccines to treat human neglected diseases is a priority for the World Health Organization and other organizations. ${ }^{1,2}$

Two of the deadliest NTDs are leishmaniasis and Chagas disease. Leishmaniasis affects 12 million people in 98 countries mainly in Africa, Asia, and Latin America. ${ }^{3,4}$ Two distinct human pathological conditions are observed for leishmaniasis, cutaneous and visceral. Leishmania (L.) infantum is the etiologic agent of visceral leishmaniasis (VL) in South America and southern Europe countries, while Leishmania (L.) donovani is in Asian and African countries. Visceral leishmaniasis promoted by L. (L.) infantum is fatal, with a mortality rate of $100 \%$ if untreated. ${ }^{4}$ Leishmaniasis is included as a target disease by DNDi (Drugs for Neglected Diseases initiative) and iOWH (Institute for One World Health).

Chagas disease is caused by Trypanosoma cruzi as a potentially fatal disorder resulting in cardiomegaly and megacolon in about $30 \%$ of the patients. ${ }^{5}$ Chagas disease remains one of the most severe public-health problems in 21 countries of Latin America, causing more than 7000 deaths per year without early and successful antiparasitic treatment. Over 25 million people are at risk of infection by $T$. cruzi and about 7 million people are infected worldwide. ${ }^{1}$ Chagas disease has spread into several European countries and Japan, probably due to population migration. Effective treatments for Chagas disease are urgently needed. ${ }^{6}$ 
Large drug screening campaigns to find new drugs to treat NTDs are currently being developed. New criteria for improving the success of clinical drug candidates with potential use in NTDs has been recently reviewed. ${ }^{7}$ While most hit compounds for infectious diseases were discovered using phenotypic assays, subsequent optimization efforts need to establish the drug target. $^{7}$ Among various classes of natural and synthetic compounds that present antiparasitic activity, guanidines have shown to be of particular interest because of their potent activity and suitable pharmacokinetic profile. ${ }^{8-11}$ Based on the findings recently reported by some of us showing potent and selective antileishmanial and antitrypanosomal activity for marine spongederived guanidine alkaloids, ${ }^{11}$ herein we report the results of the investigation of 18 synthetic guanidines as antiparasitic agents against Leishmania and Trypanosoma parasites. The two most selective synthetic guanidines active against $L$. (L.) infantum were further investigated for the mechanism of action on the parasites and for their immunomodulatory activity.

\section{RESULTS}

Antileishmanial Activity and Antitrypanosomal Activity. L. (L.) infantum promastigotes were incubated for $48 \mathrm{~h}$ with guanidines 1-18 and the viability of cells was determined by the MTT colorimetric assay. Compounds 1-18 showed $\mathrm{IC}_{50}$ values in the range between $6.6 \mu \mathrm{M}$ and to 110 $\mu \mathrm{M}$. Intracellular L. (L.) infantum amastigotes were also treated with compounds 1-18. The observed $\mathrm{IC}_{50}$ values were in the range between $0.8 \mu \mathrm{M}$ and $49 \mu \mathrm{M}$. Miltefosine was used as a standard drug $\left(\mathrm{IC}_{50}\right.$ of $\left.16 \mu \mathrm{M}\right) . T$. cruzi trypomastigotes were incubated with the same series of compounds for $24 \mathrm{~h}$ and the cell viability was determined by the resazurin assay. Guanidines 118 displayed antitrypanosomal activity with $\mathrm{IC}_{50}$ values in the range between $0.9 \mu \mathrm{M}$ and 88.5 $\mu \mathrm{M}$. These results are presented in Table 1 . Benznidazole was used as standard drug ( $\mathrm{IC}_{50}$ of $440.7 \mu \mathrm{M})$. 


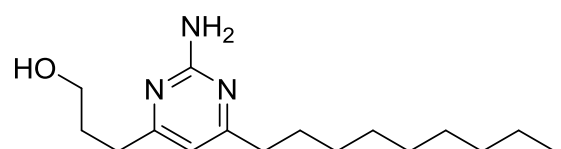

1
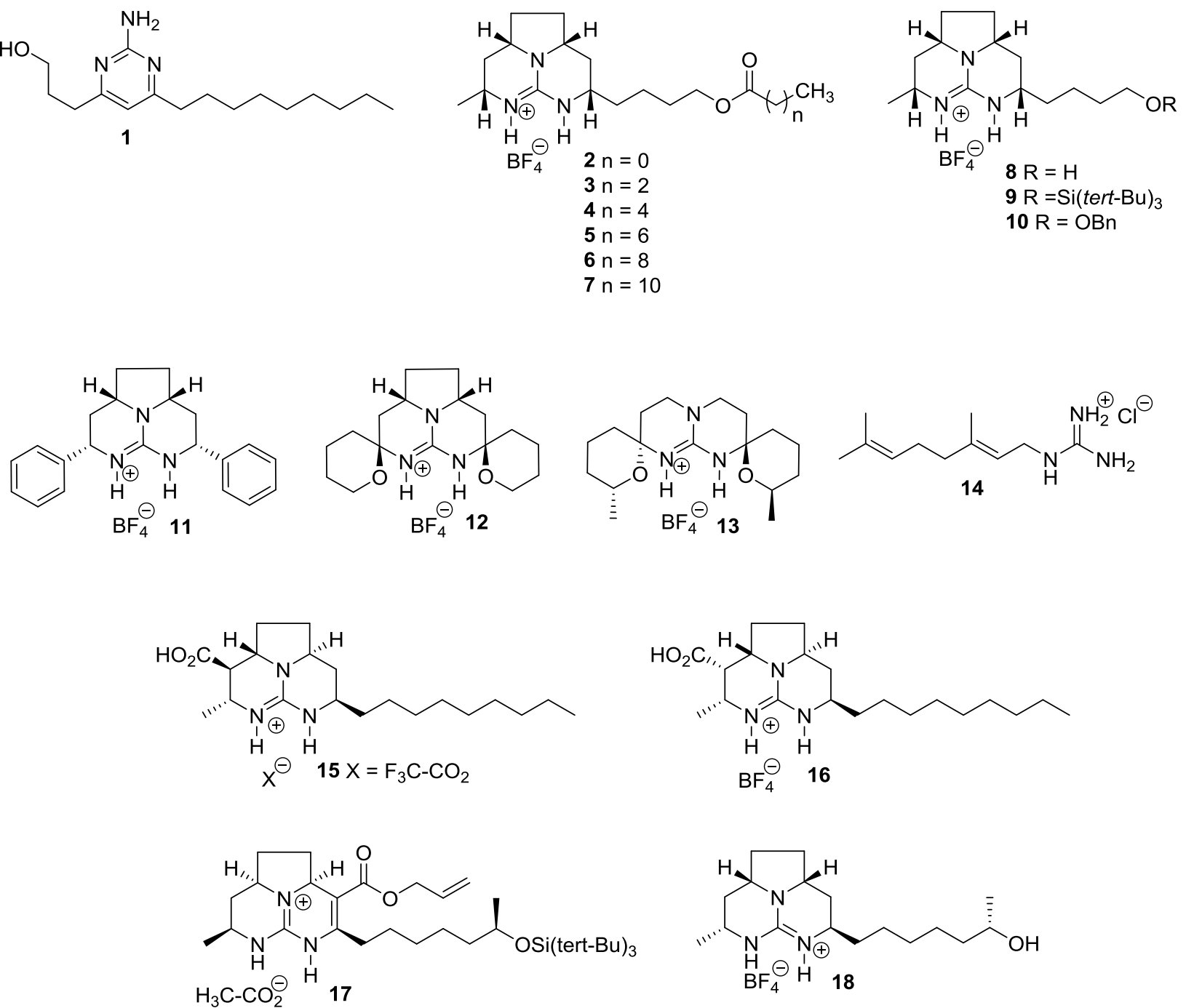

Determination of the 50\% Cytotoxic Concentration $\left(\mathrm{CC}_{50}\right)$ in Mammalian Cells. Aiming to evaluate the mammalian cytotoxicity of compounds 1-19, NCTC cells (clone 929) were incubated for $48 \mathrm{~h}$ and the cell viability was determined by the colorimetric assay method MTT. Guanidines 1-19 showed toxicity with $\mathrm{CC}_{50}$ values in the range between $2.4 \mu \mathrm{M}$ and $>150 \mu \mathrm{M}$. Miltefosine and benznidazole were used as standard drugs and showed $\mathrm{CC}_{50}$ values of $122.0 \mu \mathrm{M}$ and $469.9 \mu \mathrm{M}$, respectively (Table 1).

Immunomodulatory Potential of Compounds. Quantification of Nitric Oxide (NO).

Guanidines $\mathbf{1 0}$ and $\mathbf{1 1}$ showed the highest selectivity index (25 and 20, respectively) as 
antileishmanial agents (Table 1, Selectivity Index), and were selected for further mechanism of action assays. Compounds $\mathbf{1 0}$ and $\mathbf{1 1}$ were incubated with peritoneal macrophages and the NO content was evaluated after 24 h. Both compounds revealed no capacity to upregulate NO production (Figure 1). Bacterial lipopolysaccharide (LPS) was used as the positive control. Cellular Immune Response of $L$. (L.) infantum -Infected Macrophages Co-Cultivated with Splenocytes. Non-infected and $L$. (L.) infantum-infected macrophages were treated for $48 \mathrm{~h}$ with guanidines 10 and 11 and were co-cultived with or without splenocytes. The production of cytokines MCP-1, IL-6, IL-10, TNF and IFN- $\gamma$ was detected by flow cytometry analysis. Compound 10 decreased the production of cytokines MCP-1 $(\mathrm{p}<0.05)$ and IFN- $\gamma(\mathrm{p}<0.05)$ in both non-infected and L. (L.) infantum-infected macrophages. The same result was observed when macrophages were co-cultived with or without splenocytes. A similar downregulation effect $(\mathrm{p}<0.001)$ of MCP-1 was also observed in splenocytes incubated with guanidines $\mathbf{1 0}$ and $\mathbf{1 1}$. However, compounds $\mathbf{1 0}$ and $\mathbf{1 1}$ did not promote alteration of cytokines TNF, IL-6 and IL-10 levels (data not shown). The production of cytokine IFN- $\gamma$ was negatively modulated by $\mathbf{1 0}$ and 11 in non-infected as well as in $L .(L$.$) infantum-infected macrophages co-cultived with$ splenocytes (Figure 2).

Evaluation of Guanidines 10 and 11 Lethal Action on L. (L.) infantum. Permeability of Plasma Membrane. Guanidines 10 and 11 (57 $\mu \mathrm{M}$ and $34 \mu \mathrm{M}$, respectively), promoted alteration in plasma membrane permeability of Leishmania (L.) infantum promastigotes, measured using the fluorescent probe Sytox Green. Compound $\mathbf{1 1}$ promoted approximately $64 \%$ higher fluorescence intensity (Figure 3) after 60 min when compared to untreated parasites $(\mathrm{p}<0.001)$. Compound 10 also induced significant $(\mathrm{p}<0.001)$ increase in fluorescence intensity after 60 min of incubation, but less intense than 11 (Figure 3). 
Evaluation of Mitochondrial Membrane Potential. Alteration of L. (L.) infantum

mitochondrial membrane potential was investigated in the presence of $\mathbf{1 0}$ and $\mathbf{1 1}(57 \mu \mathrm{M}$ and 34

$\mu \mathrm{M}$, respectively). Promastigotes were incubated with both compounds separately, for 60 min and the mitochondrial membrane potential was monitored using the fluorescent probe rhodamine 123. Both compounds induced a significant reduction $(\mathrm{p}<0.001)$ of the fluorescence intensity of rhodamine 123 when compared to untreated L. (L.) infantum promastigotes. The $70 \%$ depolarization intensity caused by both compounds was similar to the level observed with the positive control sodium azide (Figure 4).

Reactive Oxygen Species (ROS) Regulation. Production of ROS by L. (L.) infantum promastigotes in the presence of guanidines $\mathbf{1 0}$ and $\mathbf{1 1}$ was determined using the fluorescent probe $\mathrm{H}_{2}$ DCF-DA. After 120 min incubation, guanidine $\mathbf{1 0}$ promoted significant alteration in $L$. (L.) infantum ROS levels ( $<<0.001)$, resulting in a 3-fold higher content than the sodium azide positive control. Compound 11 also promoted alteration of ROS levels in L. (L.) infantum, 60\% higher than in untreated parasites $(\mathrm{p}<0.05)$ (Figure 5).

\section{DISCUSSION}

Several guanidine compounds have been evaluated as antiparasitic compounds, and showed significant in vitro antileishmanial and antitrypanosomal activity when compared to standard drugs. ${ }^{11-18}$ Based on our recent discovery of a series of alkaloids from the sponge Monanchora arbuscula, active against $L$. (L.) infantum and T. cruzi parasites, ${ }^{11}$ we evaluated an additional series of nineteen synthetic guanidine derivatives against $L$. (L.) infantum and T. cruzi.

Among 18 guanidine compounds tested against T. cruzi trypomastigotes, 14 (77\%)

showed activity bellow $100 \mu \mathrm{M}$, of which compounds $\mathbf{1}, \mathbf{5}, \mathbf{6}, \mathbf{7}, \mathbf{9}, 11$ and 17 presented $\mathrm{IC}_{50}$ values below $10 \mu \mathrm{M}$. Guanidines 5, 6, 7, and 9 showed low cytotoxicity and the highest 
selectivity indexes (SI), between 12 and 28. Guanidine 17 was approximately X-fold more effective than the standard drug benznidazole. Guanidines 6 and 7 were about 120-fold more effective, presenting a trypanocidal activity observed by the lack of mitochondrial activity measured by resazurin. Other guanidine compounds were tested against $T$. cruzi and showed potent activity, in the range between 1 and $10 \mu \mathrm{M},{ }^{13}$ similarly as observed for compounds $\mathbf{1}, \mathbf{5}, \mathbf{6}$, 7, 9, 11 and 17. Compound 17 displayed potent antitrypanosomal activity, with an $\mathrm{IC}_{50}$ value of $0.95 \mu \mathrm{M}$. However, the selectivity index was below 10, and cannot attend an important criteria for the hit stage.

Guanidine compounds isolated as natural products and synthetic derivatives have also shown potent antileishmanial activity. ${ }^{14-18}$ Eleven (61\%) out of 18 synthetic guanidines herein evaluated displayed antileishmanial activity against promastigotes, 9 of which were active against L. (L.) infantum intracellular amastigotes bellow $100 \mu \mathrm{M}$. Five of these displayed $\mathrm{IC}_{50}$ values below $10 \mu \mathrm{M}(\mathbf{1}, \mathbf{1 0}, \mathbf{1 1}, 12$ and 18). Considering the recommendations of the Drugs for Neglected Diseases initiative (DNDi) for antileishmanial agents, ${ }^{19}$ an $\mathrm{IC}_{50}<10 \mu \mathrm{M}$ and selectivity index $(\mathrm{SI}) \geq 10$ are determinant features for antileishmanial compounds at the hit stage. ${ }^{19,20}$ Guanidines 10 and 11 presented SI of 25 and 20, respectively, and were selected for investigation of the lethal mechanism of action against Leishmania parasites.

Due to the complexity of intracellular amastigote defenses, an antileishmanial suitable hit compound needs to specifically target the parasite which lives in the acidic parasitophorous vacuole inside the macrophage. ${ }^{21}$ Guanidines $\mathbf{1 0}$ and $\mathbf{1 1}$ showed more potent antiparasitic activity against intracellular amastigotes than to extracellular promastigotes. In order to investigate if the antileishmanial activity of $\mathbf{1 0}$ and $\mathbf{1 1}$ against intracellular amastigotes could be ascribed to an immunomodulatory effect in host cells, we evaluated cytokine production by macrophages in the presence of guanidines $\mathbf{1 0}$ and $\mathbf{1 1}$. This approach enables to differentiate compounds that are 
directly active in the parasite from those that exert antiparasitic effect by an immunomodulatory response. $^{22}$

Immunomodulators have been investigated as drugs for the clinical treatment of leishmaniasis, but with limited efficacy when administered alone. ${ }^{23,24}$ Guanidines $\mathbf{1 0}$ and $\mathbf{1 1}$ caused no upregulation of NO in macrophages. Flow cytometry analysis indicated that $\mathbf{1 0}$ and $\mathbf{1 1}$ significantly suppressed the production of IFN- $\gamma$ and MCP-1 cytokines in the host cell, causing no significant alteration of TNF, IL-6 and IL-10 levels. Cytokines play different roles during a Leishmania infection in macrophages. In L. (L.) infantum-infected human macrophages, treatment with monocyte chemotactic protein chemokine (MCP-1) enhances NO production and the antileishmanial activity. ${ }^{25} \mathrm{MCP}-1$ is a leukocyte activator, related to the production of proinflammatory cytokines and microbicidal molecules. It promotes NO release and increased parasite killing by $T$. cruzi-infected macrophages. Upregulation of cytokine IL- 6 has been associated with a lethal outcome of the disease, preceding death in patients with visceral leishmaniasis (VL). ${ }^{26}$ High levels of IFN- $\gamma$, IL-10, and IL-6 are associated with human visceral leishmaniasis and with leishmaniasis persistence. ${ }^{27,28}$

In addition to the downregulation of inflammatory cytokines induced by guanidines $\mathbf{1 0}$ and $\mathbf{1 1}$ in Leishmania-infected macrophages co-cultived with splenocytes, both compounds promoted the death of intracellular amastigotes. Attenuation of immune response by immunomodulators, such as pentoxyfylline associated with pentavalent antimony, decrease tissue inflammation in patients, leading to a curative therapy associated with the decrease of TNF and IFN- $\gamma$ levels. ${ }^{29}$ These results suggest that guanidines $\mathbf{1 0}$ and $\mathbf{1 1}$ exert antileishmanial activity by a direct effect on parasites, promoting anti-inflammatory modulation in host cells, which might contribute to a beneficial prognosis of the disease. 
Because the antileishmanial activity of guanidines $\mathbf{1 0}$ and $\mathbf{1 1}$ was associated to other mechanisms than merely macrophage activation, we investigated possible intracellular targets in Leishmania. Damage to the plasma membrane and mitochondria was then evaluated using different fluorescent probes, as mitochondria are unique machinery in protozoan parasites and have been shown as a potential target for antiparasitic drugs. ${ }^{30-33}$ The permeability of the $L .(L$. infantum plasma membrane was observed using green-fluorescent nuclear and chromosome counter stain, which does not enter live cells and exhibits $>500$-fold fluorescence enhancement after binding nucleic acids. ${ }^{34}$ Both guanidines $\mathbf{1 0}$ and $\mathbf{1 1}$ increased fluorescence levels, indicating the promotion of increased membrane permeabilization within 60 min of incubation.

The mitochondrial membrane potential is crucial for ATP generation in the respiratory chain. ${ }^{33}$ In contrast to mammalian cells, where the presence of multiple mitochondria ensures compensation for functionally impaired ones, trypanosomatids present a single mitochondrion. ${ }^{30}$ We investigated the effects of $\mathbf{1 0}$ and $\mathbf{1 1}$ on Leishmania mitochondria at initial contact. Both compounds $\mathbf{1 0}$ and $\mathbf{1 1}$ induced rapid depolarization of the mitochondrial membrane potential to levels similar to the positive control. Amphotericin B, used in the treatment of leishmaniasis, also increases permeability of the Leishmania plasma membrane, followed by a rapid decrease in the mitochondrial membrane potential. ${ }^{35}$ Paromomycin significantly decreases the mitochondrial membrane potential of Leishmania, indicating that this organelle might be the ultimate drug target. $^{31,32}$

Leishmania parasites present various defense mechanisms to cope with oxidative stress, including expression of antioxidant enzymes such as trypanothione $\left(\mathrm{T}(\mathrm{SH})_{2}\right),{ }^{36}$ superoxide dismutase ${ }^{37}$ peroxidases ${ }^{38}$ trypanothione S-transferase ${ }^{39}$ and 6-phosphogluconate dehydrogenase $(6 \mathrm{PGDH}) .{ }^{40}$ These enzymes, including iron superoxide dismutase and peroxiredoxin, are located in the mitochondria. ${ }^{41}$ During oxidative stress, excessive amounts of reactive oxygen species 
(ROS) are produced in the mitochondria. These oxidant components, including superoxide radical $\left(\mathrm{O}_{2}{ }^{--}\right)$, hydrogen peroxide $\left(\mathrm{H}_{2} \mathrm{O}_{2}\right)$, hydroxyl radical $\left(\mathrm{HO}^{\circ}\right)$, hypochlorite $\left(\mathrm{OCl}^{-}\right)$and peroxynitrite $\left(\mathrm{ONOO}^{-}\right)$, are reactive signaling chemicals that accumulate under pathological conditions and lead to oxidative stress caused by dysfunction of the Leishmania mitochondrial respiratory chain. ${ }^{42}$ Guanidine $\mathbf{1 0}$ was the most effective compound at enhancing ROS levels in Leishmania, while $\mathbf{1 1}$ showed a similar effect but to a lesser extent when compared to the positive control (sodium azide). Our results are in agreement with the mechanism of action (MoA) of other guanidines in protozoan. The antimalarial guanidine proguanil collapse the mitochondrial membrane potential of the parasite Plasmodium, the etiologic agent of malaria. ${ }^{45}$ Considering similar effects in mitochondria, it seems probable that the guanidines herein investigated affect the respiratory system of Leishmania, leading to parasite death. This outcome may be a useful strategy to kill protozoans, as these microorganisms present a single mitochondrion. The capacity of these compounds to induce parasite death in the intracellular form without host cell activation is another significant outcome, important to provide new drug candidates useful to treat immunodeficient patients.

A series of 18 guanidines tested against $T$. cruzi and $L$. (L.) infantum parasites provided an elevated number of selective hits, with $\mathrm{IC}_{50}$ values below $10 \mu \mathrm{M}$. The two most active antileishmanial guanidines, compounds $\mathbf{1 0}$ and $\mathbf{1 1}$, induce depolarization of the mitochondrial membrane potential, promoting a strong alteration of ROS levels in Leishmania parasites. Despite an effective detoxification system of these parasites, if not rapidly scavenged the accumulated ROS are able to induce strong cellular damage. This effect might contribute to oxidative stress induced by guanidines $\mathbf{1 0}$ and 11, leading to $L$. (L.) infantum elimination. A computational study was performed to predict Pan-Assay Interference Compounds (PAINS), but none of the compounds was predicted as PAINS. The in silico studies, the in vitro potency of 
guanidines $\mathbf{1 0}$ and $\mathbf{1 1}(<10 \mu \mathrm{M})$, a selectivity index $>10$, as well as the respective MoA against Leishmania parasites without affecting host cells, allow us to select these compounds as possible hits for future investigations. Further experiments are in progress in order to gather information about ADMET properties and in vivo efficacy of compounds $\mathbf{1 0}$ and $\mathbf{1 1}$. Results will be reported in due time.

\section{EXPERIMENTAL SECTION}

Chemicals. 3-(4,5-dimethylthiazol-2-yl)-2,5-diphenyltetrazolium bromide (thiazolyl blue; MTT), resazurin (Alamar blue), SYTOX Green, Rhodamine 123 and $\mathrm{H}_{2}$ DCFDA were purchased from Molecular Probes. Giemsa stain, DMSO and MeOH were obtained from Merck. RPMI-1640 medium, M-199 medium, Hanks balanced salts, phosphate-buffered saline (PBS), trypan blue stain and miltefosine were obtained from Sigma (Brazil). Other reagents were purchased from Sigma Aldrich (Brazil). The Cytometric Beads Array (CBA, Mouse Inflammation Kit Biosciences) was from Becton Dixon.

Synthesis of Substrate Compounds. Guanidines 1-18 were tested as antileishmanial and antitrypanosomal compounds. Pyrimidine 1, tricyclic guanidines 2-10, pentacyclic guanidine 16 and tetracyclic guanidine 17 were prepared as previously described. ${ }^{46-52}$ The naturally occurring

guanidine alkaloid nitensidine D $(\mathbf{1 8})^{52}$ was prepared as its hydrochloride salt in $53 \%$ yield by the reaction of geranylamine with $1 H$-pyrazole-1-carboxamidine hydrochloride.

General Bioassays Procedures. Golden hamsters and BALB/c mice were obtained by the animal breeding facility at the Adolfo Lutz Institute-SP, Brazil. The animals were maintained in sterilized cages under a controlled environment, and received water and food ad libitum. Animal procedures were performed with the approval of the Research Ethics Commission (project 
number CEUA IAL/Pasteur 02/2011), in agreement with the Guide for the Care and Use of Laboratory Animals from the National Academy of Sciences.

Parasites and Mammalian Cell Maintenance. L. (L.) infantum (MHOM/BR/1972/LD) was maintained in Golden hamsters (Mesocricetus auratus) up to approximately 60-70 days postinfection. Promastigotes were maintained in M-199 medium supplemented with 10\% fetal calf serum and $0.25 \%$ hemin at $24{ }^{\circ} \mathrm{C}$. Amastigotes were obtained from the spleen of previously infected hamsters and purified by differential centrifugation. Macrophages were collected from the peritoneal cavity of BALB/c mice by washing them with RPMI-1640 medium supplemented with $10 \%$ fetal calf serum, and were maintained at $37{ }^{\circ} \mathrm{C}$ in a $5 \% \mathrm{CO}_{2}$-humidified incubator. Trypomastigotes of T. cruzi (Y strain) were maintained in Rhesus-monkey kidney cells (LLCMK2 - ATCC CCL 7), cultivated in RPMI-1640 medium supplemented with 2\% fetal calf serum at $37{ }^{\circ} \mathrm{C}$ in $5 \% \mathrm{CO}_{2}$-humidified incubator. The murine conjunctive cells (NCTC clone 929, ATCC) were maintained in RPMI-1640 supplemented with $10 \% \mathrm{FBS}$ at $37{ }^{\circ} \mathrm{C}$ in a humidified atmosphere containing $5 \% \mathrm{CO}_{2}$. NCTC - clone 929 cells were cultivated in M-199 medium, supplemented with $10 \%$ fetal calf serum at $37{ }^{\circ} \mathrm{C}$ in $5 \% \mathrm{CO}_{2}$-humidified incubator.

Determination of the 50\% Inhibitory Concentration $\left(\mathrm{IC}_{50}\right)$. Promastigotes: Promastigotes in late growth-phase (non-stationary at $3 \times 10^{7} / \mathrm{mL}$, passage 5 ) were counted in a hemocytometer chamber and seeded at $1 \times 10^{6} /$ well, with a final volume of $150 \mu \mathrm{L}$. The compounds were dissolved in DMSO and diluted in M-199 medium in 96-well microplates, with the highest concentration of $150 \mu \mathrm{M}$ for $48 \mathrm{~h}$ at $24^{\circ} \mathrm{C}$. The parasite viability was determined using the MTT colorimetric assay. ${ }^{53}$ The optical density was read at $570 \mathrm{~nm}$ (FilterMax F5 Multi-Mode Microplate Reader, Molecular Devices) using control wells without drugs (100\% viability) and without cells (blank). The control group consisted of promastigotes incubated with 0.5\% DMSO. Miltefosine was used as a standard drug. Compounds were tested to the highest concentration of 
$100 \mu \mathrm{M}$ and were reported as NA (not active) when the $\mathrm{IC}_{50}$ value was above this concentration. Amastigotes: Peritoneal macrophages were collected from the peritoneal cavity of BALB/c mice, and the macrophages were seeded at $1 \times 10^{5}$ /well for $24 \mathrm{~h}$ in a 16 -well slide. Amastigotes were prepared as described previously in a 1:10 ratio of macrophages to amastigotes for $24 \mathrm{~h}$ at $37^{\circ} \mathrm{C}$ $5 \% \mathrm{CO}_{2}$-humidified incubator. The compounds were incubated with infected macrophages for 120 h. Miltefosine was used as standard drug. Subsequently, the cells were fixed with $\mathrm{MeOH}$, stained with Giemsa and observed using a light microscope. The parasite burden was determined by the number of infected macrophages out of 400 cells. ${ }^{20}$ Compounds were tested to the highest concentration of $100 \mu \mathrm{M}$ and were reported as NA (not active) when the $\mathrm{IC}_{50}$ value was above this concentration.

Trypomastigotes of $\boldsymbol{T}$. cruzi. Free trypomastigotes were counted in a hemocytometer chamber and seeded at $1 \times 10^{6}$ cells per well in 96-well microplates. The compounds were diluted in RPMI-1640 medium and incubated in highest concentrations to $150 \mu \mathrm{M}$ for $24 \mathrm{~h}$ at $37^{\circ} \mathrm{C}$ in a $5 \%$ $\mathrm{CO}_{2}$-humidified incubator. The parasite viability was determined using the resazurin $(0.011 \%$ in PBS). ${ }^{54}$ The optical density was read at $570 \mathrm{~nm}$ using control wells without drugs $(100 \%$ viability) and without cells (blank). The control group consisted of trypomastigotes incubated with $0.5 \%$ DMSO. Benznidazole was used as a standard drug. Compounds were tested to the highest concentration of $100 \mu \mathrm{M}$ and were reported as NA (not active) when the $\mathrm{IC}_{50}$ value was above this concentration.

Cytotoxicity in Mammalian Cells. NCTC cells were counted in a hemocytometer chamber, seeded at $6 \times 10^{4} /$ well and incubated in highest concentrations to $150 \mu \mathrm{M}$ for $48 \mathrm{~h}$ at $37^{\circ} \mathrm{C}$ in a $5 \% \mathrm{CO}_{2}$-humidified incubator. The cell viability was determined using the MTT assay. ${ }^{53}$ Miltefosine was used as standard drug. The selectivity index (SI) was determined using the relationship, $\mathrm{CC}_{50}$ against $\mathrm{NCTC} / \mathrm{IC}_{50}$ against parasites. 
Evaluation of Plasma Membrane Permeability. Late growth-phase (non-stationary at $3 \mathrm{x}$ $10^{7} / \mathrm{mL}$, passage 7) promastigotes were washed in PBS, seeded at $2 \times 10^{6} /$ well and incubated with $1 \mu \mathrm{M}$ SYTOX Green for $15 \mathrm{~min}$ at $24{ }^{\circ} \mathrm{C} .{ }^{34}$ The compounds $\mathbf{1 0}$ and $\mathbf{1 1}$ were added at their respective $\mathrm{IC}_{50}$ values $(57 \mu \mathrm{M}$ and $34 \mu \mathrm{M}$, respectively), and the fluorescence was measured every $20 \mathrm{~min}$ for $60 \mathrm{~min}$ total. The maximum permeabilization was obtained with $0.1 \%$ Triton $\mathrm{X}$ 100. Fluorescence intensity was determined using a fluorimetric microplate reader (FilterMax F5 Multi-Mode Microplate Reader, Molecular Devices) with excitation and emission wavelengths of 485 and $520 \mathrm{~nm}$, respectively. The following internal controls were used in the evaluation: (i) the background fluorescence of test compounds, (ii) the possible interference of DMSO, (iii) untreated promastigotes, and (iv) medium without any cells. Samples were tested in triplicate. ${ }^{55}$ Evaluation of Mitochondrial Membrane Potential. The change in mitochondrial membrane potential in intact promastigotes was estimated by measuring rhodamine- 123 accumulation. ${ }^{56}$ Parasites $\left(2 \times 10^{6}\right.$ promastigotes $\left./ \mathrm{mL}\right)$ were resuspended in Hanks Balanced Salt Solution-Glucose (HBSS-Glc) and incubated with the $\mathbf{1 0}$ and $\mathbf{1 1}$ at the respective $\mathrm{IC}_{50}$ values $(57 \mu \mathrm{M}$ and $34 \mu \mathrm{M}$, respectively) for $60 \mathrm{~min}$ at $25^{\circ} \mathrm{C}$. Subsequently parasites were incubated with rhodamine-123 for $10 \mathrm{~min}\left(0.3 \mu \mathrm{g} / \mathrm{mL}, 5 \mathrm{~min}, 37^{\circ} \mathrm{C}\right)$, washed by centrifugation, and resuspended in HBSS-Glc and the fluorescence was determined using a fluorimetric microplate reader with excitation and emission wavelengths of 485 and $520 \mathrm{~nm}$, respectively. Sodium azide $(10 \mathrm{mM})$ was used as the positive control. ${ }^{57}$ The following internal controls were used in the evaluation: (i) the background fluorescence of test compound, (ii) the possible interference of DMSO, (iii) untreated promastigotes, and (iv) medium without any cells. Samples were tested in triplicate.

Detection of ROS. Promastigotes ( 2 x 10\% $/$ well) were washed with HBSS and incubated with 10 and 11 at the respective $\mathrm{IC}_{50}$ values $\left(57 \mu \mathrm{M}\right.$ and $34 \mu \mathrm{M}$, respectively) for $60 \mathrm{~min} . \mathrm{H}_{2} \mathrm{DCFDA}$ was added $(5 \mu \mathrm{M})$, and the cells were incubated for $15 \mathrm{~min}$. Fluorescence intensity was evaluated 
using a fluorimetric microplate reader with excitation and emission wavelengths of 485 and 520 $\mathrm{nm}$, respectively. Sodium azide $(10 \mathrm{mM})$ was used as the positive control ${ }^{58-60}$ The following internal controls were used in the evaluation: (i) the background fluorescence of test compounds, (ii) the possible interference of DMSO, (iii) untreated promastigotes, and (iv) medium without any cells. Samples were tested in triplicate.

Quantification of Nitric Oxide. Nitric oxide (NO) content was measured in the culture supernatants from peritoneal macrophages treated with compounds $\mathbf{1 0}$ and $\mathbf{1 1}$ at the respective $\mathrm{IC}_{50}$ values (intracellular amastigote assay $=5 \mu \mathrm{M}$ and $2 \mu \mathrm{M}$, respectively) for $24 \mathrm{~h}$ and analyzed by Griess assay. ${ }^{61}$ Results obtained were extrapolated from a standard curve prepared with $\mathrm{NaNO}_{2}$ at different concentrations $(0$ to $400 \mu \mathrm{M})$. Bacterial lipopolysaccharide (LPS) $(1 \mu \mathrm{g} / \mathrm{mL})$ was used as a positive control. Samples were tested in triplicate.

\section{Cellular Immune Response Assay. Peritoneal Macrophages Co-Cultived with Splenocytes}

and In Vitro Infection. Peritoneal macrophages were isolated from BALB/c mice and seeded into the 24 -well plate at $1.5 \times 10^{5} /$ well. After $24 \mathrm{~h}$ L. (L.) infantum amastigotes were used to infect the cells at a 1:10 ratio (macrophage/amastigotes) ${ }^{20}$ After $24 \mathrm{~h}$ infected macrophages were co-cultivated with splenocytes at a concentration of 6:1. Preparations were obtained by crushing spleens in PBS (pH 7.2). Subsequently, splenocyte suspensions were washed twice with PBS and erythrocytes were lysed with Ammonium-Chloride-Potassium (ACK) buffer ( $0.15 \mathrm{M} \mathrm{NH}{ }_{4} \mathrm{Cl} ; 10$ $\mathrm{mM} \mathrm{KHCO}_{3} ; 0.1 \mathrm{M} \mathrm{Na} 2 \mathrm{EDTA}$ ) for $5 \mathrm{~min}$. After washing two times with PBS by centrifugation at $4{ }^{\circ} \mathrm{C}$ for $10 \mathrm{~min}$, the cells were resuspended in RPMI 1640 medium and $10 \%$ heat-inactivated fetal calf serum. The viability of the cells used in the experiments was always higher than $85 \%$, as measured by trypan blue exclusion. After $48 \mathrm{~h}$ with compounds $\mathbf{1 0}(30 \mu \mathrm{M})$ and $\mathbf{1 1}(15 \mu \mathrm{M})$, supernatants were collected to perform the cytokine assay. Proteins levels were determined using an inflammatory Cytometric Beads Array (CBA) Kit according to the manufacturer's instructions. 
The concentrations of the released mediators were measured: Interleukin-6 (IL-6), Interleukin- 10 (IL-10), monocyte chemotactic protein-1 chemokine (MCP-1), Interferon- $\gamma$ (IFN- $\gamma$ ), Tumor Necrosis Factor (TNF), and Interleukin-12p70 (IL-12p70) using flow cytometry. Sham-treated macrophages infected with $L .(L$.$) infantum were used as controls.$

Statistical Analysis. The results are represented as the mean and standard deviation of replicates samples from at least two independent assays. The $\mathrm{IC}_{50}$ values were calculated using sigmoidal dose-response curves using GraphPad Prism 5.0 software. The 95\% confidence interval is included in parentheses with the analyses. The Test $\mathrm{T}$ was used for significance testing $(\mathrm{p}<0.05)$

\section{ASSOCIATED CONTENT}

Supporting Information available: procedure for preparation of compound 14. ${ }^{1} \mathrm{H}$ and ${ }^{13} \mathrm{C}$ NMR spectra for compounds XX (not previously published). The Supporting Information is available free of charge on the ACS Publications website at DOI:

\section{AUTHOR INFORMATION}

\section{Corresponding Author}

*Telephone: (55+11) 3068-2974; Fax: (55+11) 3068-2890; e-mail: atempone@ usp.br.

\section{Present address}

${ }^{\dagger}$ (A.G.T.) Center for Parasitology and Mycology, Instituto Adolfo Lutz, Avenida Dr. Arnaldo, 351, $8^{\circ}$ andar, 01246-000 São Paulo, Brasil.

\section{Notes}

The authors declare no competing financial interest. 


\section{ACKNOWLEDGEMENTS}

The authors thank to the São Paulo Research Foundation (FAPESP) for financial support (grants 2012/18756-1 and 2013/50228-8 for AGT and RGSB, respectively; scholarships 2011/23703-1 and 2013/07275-5). AGT, RGSB and CHA thank the Conselho Nacional de Desenvolvimento Científico e Tecnológico for scientific awards. ERDF BEACON project (PJM), the European Social Fund KESS project (ELB), the EPSRC (GPB, DAT), AstraZeneca (DAT), Pfizer (GPB) and the Libyan Authority for Research, Science \& Technology are also gratefully acknowledged. The authors would like to thank Goias Research Foundation (FAPEG) and ACD/I-Labs for providing credits to use their server.

\section{REFERENCES}

(1) World Health Organization. Investing to overcome the global impact of neglected tropical diseases: third WHO report on neglected diseases; World Health Organization: Geneva, 2015.

(2) Barrett, M.P.; Croft, S.L. Parasitol. 2014, 141, 1-7.

(3) Da Silva Filho, A. A.; Resende, D. O.; Fukui, M. J.; Santos, F. F.; Pauletti, P. M.; Cunha, W. R.; Silva, M. L.; Gregório, L. E.; Bastos, J. K.; Nanayakkara, N. P. Fitother. 2009, 80, 478-482.

(4) World Health Organization. Control of the Leishmaniases; WHO Technical Report Series; WHO: Geneve, 2010.

(5) Tempone, A. G.; Sartorelli, P.; Mady, C.; Fernandes, F. Cardiovasc. Hematol. Agents Med. Chem. 2007, 5, 222-235.

(6) World Health Organization. Chagas disease (American trypanosomiasis) fact sheet. Wkly Epidemiol Rec., WHO Technical Report Series; WHO: Geneve, 2010. (7) Katsuno, K.; Burrows, J. N.; Duncan, K.; van Huijsduijnen, R. H.; Kaneko, T.; Kita, K.; 
Mowbray, C. E.; Schmatz, D.; Warner, P.; Slingsby, B. T. Nat. Rev. Drug. Discov. 2015, 14, 751758.

(8) Saczewski, F.; Balewski, L. Expert. Opin. Ther. Pat. 2009, 19, 1417-1448.

(9) Sączewski, F.; Balewski, L. Expert. Opin. Ther. Pat. 2013, 23, 965-995.

(10) Choon, H. T.; Coles, M.; Dugan, P. Aust. J. Chem. 2014, 67, 7.

(11) Santos, M. F.; Harper, P. M.; Williams, D. E.; Mesquita, J. T.; Pinto, E. G.; da Costa-Silva, T. A.; Hajdu, E.; Ferreira, A. G.; Santos, R. A.; Murphy, P. J.; Andersen, R. J.; Tempone, A. G.; Berlinck, R. G. J. Nat. Prod. 2015, 22, 1101-1111.

(12) Coleman, R. E.; Edman, J. D.; Semprevivo, L. H. Ann. Trop. Med. Parasitol. 1989, 83, 339344.

(13) Espírito Santo, R. D.; Machado, M. G. M.; dos Santos, J. L.; González, E. R. P.; Chin, C. M. Curr. Org. Chem. 2014, 18, 2572-2602.

(14) Barrosa, K. H.; Pinto, E. G.; Tempone, A. G.; Martins, E. G.; Lago, J. H. Planta Med. 2014, $80,1310-1314$

(15) Gonzalez, J. L.; Stephens, C. E.; Wenzler, T.; Brun, R.; Tanious, F. A.; Wilson, W.; Barszcz, T.; Werbovetz, K. A.; Boykin, D. W. Eur. J. Med. Chem. 2007, 42, 552-557.

(16) Ahmed, N.; Brahmbhatt, K. G.; Khan, S. I.; Jacob, M.; Tekwani, B. L.; Sabde, S.; Mitra, D.; Singh, I. P.; Khan, I. A.; Bhutani, K. K. Chem. Biol. Drug. Des. 2013, 81, 491-498.

(17) Hua, H. M.; Peng, J.; Fronczek, F. R.; Kelly, M.; Hamann, M. T. Bioorg. Med. Chem. 2004, $12,6461-6464$.

(18) Stephens, C. E.; Brun, R.; Salem, M. M.; Werbovetz, K. A.; Tanious, F.; Wilson, W. D.; Boykin, D. W. Med. Chem. Lett. 2003, 16, 2065-2069.

(19) Don, R.; Ioset, J. R. Parasitol. 2014, 140,140-146.

(20) Tempone, A. G.; de Oliveira, C. M.; Berlinck, R. G. S. Planta Med. 2011, 77, 572-585. 
(21) Aulner, N.; Danckaert, A.; Rouault-Hardoin, E.; Desrivot, J.; Helynck, O.; Commere, P. H.; Munier-Lehmann, H.; Späth, G. F.; Shorte, S. L.; Milon, G.; Prina, E. PLoS Negl. Trop. Dis. 2013, 47, e2154.

(22) Kedzierski, L.; Evans, K. J. Parasitol. 2014, 30, 1-19.

(23) Santarem, A. A; Greggianin, G. F.; Debastiani, R. G.; Ribeiro, J. B.; Polli, D. A.; Sampaio, R. N. Rev. Soc. Bras. Med. Trop. 2014, 47, 517-520.

(24) de Sá Oliveira, T.; Capp Neto, M.; Martins, B. J.; Rodrigues, H. A.; Antonino, R. M.;

Magalhães, A. V. Mem. Inst. Osw. Cruz. 2000, 95, 477-482.

(25) Brandonisio, O.; Panaro, M. A.; Fumarola, I.; Sisto, M.; Leogrande, D.; Acquafredda, A.; Spinelli, R.; Mitolo, V. Clin. Exp. Med. 2002, 2, 2125-2129.

(26) Costa, D. L; Rocha, R. L.; Carvalho, R. M.; Lima-Neto, A. S.; Harhay, M. O.; Costa, C. H.; Barral-Neto, M.; Barral, A.P. Pathog. Glob. Health 2013, 107, 78-87.

(27) Ansari, N. A.; Saluja, S.; Salotra, P. Clin. Immunol. 2006, 119, 339-345.

(28) Verma, S.; Kumar, R.; Katara, G. K.; Singh, L. C.; Negi, N. S.; Ramesh, V.; Salotra, P. PLoS One. 2010, 9, e10107.

(29) Brito, G.; Dourado, M.; Polari, L.; Celestino, D.; Carvalho, L. P.; Queiroz, A.; Carvalho, E. M.; Machado, P. R.; Passos, S. Am. J. Trop. Med. Hyg. 2014, 90, 617-620.

(30) Fidalgo, L. M.; Gille, L. Pharm. Res. 2011, 28, 2758-70.

(31) Jhingran, A.; Chawla, B.; Saxena, S.; Barrett, M. P.; Madhubala, R. Mol. Biochem. Parasitol. 2009, 164, 111-117.

(32) Croft, S. L.; Sundar, S.; Fairlamb, A. H. Clin. Microbiol. Rev. 2006, 19, 111-126.

(33) Joshi, D.C.; Bakowska, J.C. J. Vis. Exp. 2011, 23, 51.

(34) Mangoni, M. L.; Saugar, J. M.; Dellisanti, M.; Barra, D.; Simmaco, M.; Rivas, L. J. Biol. Chem. 2005, 280, 984-990. 
(35) Lee, N.; Bertholet, S.; Debrabant, A.; Muller, J.; Duncan, R.; Nakhasi, H. L. Cell Death Differ. 2002, 9, 53-64.

(36) Olin-Sandoval, V.; Moreno-Sánchez, R.; Saavedra, E. Curr. Drug Targets. 2010, 11, 16141630.

(37) Mehlotra, R. K. Crit. Rev. Microbiol. 1996; 22, 295-314.

(38) Krauth-Siegel, L. R.; Comini, M. A.; Schlecker, T. Subcell. Biochem. 2007, 44, 231-251.

(39) Vickers, T. J.; Fairlamb, A. H. J. Biol. Chem. 2004, 279, 27246-27256.

(40) Dardonville, C.; Rinaldi, E.; Hanau, S.; Barrett, M. P.; Brun, R.; Gilbert, I. H. Bioorg. Med. Chem. 2003, 11, 3205-3214.

(41) Castro, H.; Teixeira, F.; Romao, S.; Santos, M.; Cruz, T.; Flórido, M.; Appelberg, R.;

Oliveira, P.; Ferreira-da-Silva, F.; Tomás, A. M. PLoS Pathog. 2011, 7, e1002325.

(42) Mesquita, J. T.; Pinto, E. G.; Taniwaki N. N.; Galisteo Jr, A. J.; Tempone A. G. Acta Trop. 2013, $128,666-673$.

(45) Bridges, H. R.; Jones, A. J.; Pollak, M. N.; Hirst, J. Biochem. J. 2014, 15, 475-87.

(46) Black, G. P.; Murphy, P. J.; Walshe, N. D. A.; Hibbs, D. E.; Hursthouse M. B.; Malik, K. M. A. Tetrahedron Lett., 1996, 37, 6943.

(47) Black, G. P.; Murphy, P. J.; Walshe, N. D. A. Tetrahedron 1998, 54, 9481.

(48) Caukett, P.; Howard-Jones, A.; Murphy, P. J.; Thomas, D. J. Org. Chem. 1999, 64, 1039.

(49) Black, G. P.; Coles, S. J.; Hizi, A.; Howard-Jones, A. G.; Hursthouse, M. B.; McGown, A.

T.; Loya, S.; Moore, C. G.; Murphy, P. J.; Smith N. K.; Walshe N. D. A. Tetrahedron Lett., 2001, 42,3377 .

(50) Allingham, M. T.; Howard-Jones, A.; Murphy, P. J.; Thomas, D. A.; Caulkett, P. W. R. Tetrahedron Lett., 2003, 44, 8677-8680. 
(51) Bennett, F. E. L.; Black, G. P.; Browne, P.; Hizi, A.; Jaffar, M.; Leyland, J. P.; Martin, C. Oz-Gleenberg, I.; Murphy, P. J.; Roberts, T. D.; Thornhill A. J.; Vale S. A. Tetrahedron 2013, 69, 3061-3066.

(52) Regasini, L. O.; Gamboa, I. C.; Silva, D. H. S.; Furlan, M.; Barreiro, E. J.; Ferreira, P.; M. P.; Pessoa, C.; Lotufo, L. V. C.; Moraes, M. O.; Young M. C. M.; Bolzani, V. S. J. Nat. Prod. 2009, 72, 473-476.

(53) Tada, H.; Shiho, O.; Kuroshima, K.; Koyama, M.; Tsukamoto, K. J. Methods. Immunol. 1986. $93,157-165$.

(54) Mikus, J.; Steverding, D. Parasitol. Int. 2000, 3, 265-269.

(55) Kulkarni, M. M.; Reddy, N.; Gude, T.; McGwire, B. S. Parasitol. Res. 2013, 5, 2095-2099.

(56) Luque-Ortega, J. R.; Rivero-Lezcano, O. M.; Croft, S. L.; Rivas, L. Antimicrob Agents Chemother. 2001, 45, 1121-1125.

(57) Luque-Ortega, J. R.; Rivas, L. Meth. Mol. Biol. 2010, 25, 393-491.

(58) Coimbra, E. S.; Gonçalves-da-Costa, S. C.; Corte-Real, S.; De Freitas, F. G.; Durão, A. C.; Souza, C. S.; Silva-Santos, M. I.; Vasconcelos, E. G. Parasitol. 2002, 124, 137-143.

(59) al Tuwaijri, A. S.; al Mofleh, I. A.; Mahmoud, A. A. J. Med. Microbiol. 1990, 32, 189-93.

(60) Saraiva, E. M.; Vannier-Santos, M. A.; Silva-Filho, F. C.; de Souza, W. J. Cell. Sci. 1989, $93,481-489$.

(61) Lezama-Dávila, C. M.; Isaac-Márquez A. P.; Barbi J.; Cummings, H. E.; Lu B.; Satoskar, A. R. Immunol Cell Biol. 2008, 86, 539-543. 
Table 1: Antileishmanial/Antitrypanosomal Activities and Mammalian Cytotoxicity of Guanidines and the Standard Drugs Benznidazole and Miltefosine.

\begin{tabular}{|c|c|c|c|c|c|c|}
\hline \multirow[t]{3}{*}{ Compounds } & \multirow{3}{*}{$\begin{array}{c}T . \text { cruzi } \\
\text { trypomastigote } \\
\mathbf{s}^{\mathrm{a}} \\
\mathrm{IC}_{50}(\boldsymbol{\mu M}) \\
95 \% \mathrm{CI}\end{array}$} & \multirow{3}{*}{$\begin{array}{c}L .(L .) \text { infantum } \\
\text { promastigotes }^{\text {b }}\end{array}$} & \multirow{3}{*}{$\begin{array}{c}\text { L. (L.) infantum } \\
\text { amastigotes } \\
\mathrm{IC}_{50}(\mu \mathrm{M}) \\
95 \% \mathrm{CI}\end{array}$} & \multirow{3}{*}{$\begin{array}{c}\text { NCTC cells } \\
\mathrm{CC}_{50}(\mu \mathrm{M}) \\
95 \% \mathrm{CI}\end{array}$} & \multicolumn{2}{|c|}{ Selectivity index } \\
\hline & & & & & $\mathrm{c}$ & $\mathrm{d}$ \\
\hline & & & & & & \\
\hline 1 & $8(7-9)$ & $42(36-49)$ & $5(2-14)$ & $42(35-51)$ & 8 & 5 \\
\hline 2 & $88(65-119)$ & NA & NA & $>150$ & ND & $>2$ \\
\hline 3 & $49(43-56)$ & NA & NA & $>150$ & ND & $>2$ \\
\hline 4 & $22(21-24)$ & $109(97-123)$ & NA & $>150$ & ND & $>7$ \\
\hline 5 & $8(8-8)$ & $53(45-64)$ & NA & $100(93-107)$ & ND & 12 \\
\hline 6 & $4(2-9)$ & $59(47-74)$ & NA & $84(80-88)$ & ND & 28 \\
\hline 7 & $4(4-7)$ & $48(39-61)$ & NA & $57(45-71)$ & ND & 19 \\
\hline 8 & NA & NA & NA & $>150$ & ND & ND \\
\hline 9 & $4(4-5)$ & $7(4-10)$ & $18(15-21)$ & $65(58-73)$ & 4 & 16 \\
\hline 10 & $41(36-47)$ & $57(50-65)$ & $5(4-7)$ & $138(115-164)$ & 25 & 3 \\
\hline 11 & $9(8-10)$ & $34(30-39)$ & $2(1-4)$ & $45(42-49)$ & 20 & 5 \\
\hline 12 & NA & NA & $8(6-12)$ & $>150$ & $>19$ & ND \\
\hline 13 & NA & NA & NA & $>150$ & ND & ND \\
\hline 14 & $35(31-41)$ & $9(9-10)$ & $19(6-56)$ & $116(105-128)$ & 6 & 3 \\
\hline 15 & $79(31-197)$ & $57(50-65)$ & $24(23-25)$ & $70(57-85)$ & 3 & 0.9 \\
\hline 16 & $69(55-86)$ & $47(40-54)$ & NA & $60(46-79)$ & ND & 0.9 \\
\hline 17 & $0.9(0.9-10)$ & NA & $0.8(0.3-2)$ & $2(2-3)$ & 3 & 2 \\
\hline 18 & NA & NA & $49(34-72)$ & $>150$ & $>3.0$ & ND \\
\hline benznidazole & Repetindo & ND & ND & & 15 & 1 \\
\hline miltefosine & ND & $16(15-17)$ & $17(12-24)$ & $122(95-157)$ & 7 & ND \\
\hline
\end{tabular}

Cell viability was determined using the resazurin ${ }^{\mathrm{a}}$ and $\mathrm{MTT}^{\mathrm{b}}$ assays. $\mathrm{IC}_{50}: 50 \%$ Inhibitory Concentration - concentration of compound required to reduce $50 \%$ of parasites. $\mathrm{CC}_{50}: 50 \%$ Cytotoxic Concentration- concentration of compound that reduces the viability of mammalian cells by $50 \%$. All data represent mean values for at least two separate experiments. SI: Selectivity Index- ratio of $\mathrm{CC}_{50} / \mathrm{IC}_{50}$; c- Leishmania amastigotes; d- Trypanosoma cruzi trypomastigotes. 95\% CI- 95\% Confidence Interval. NA- not active to the highest concentration of $100 \mu \mathrm{M}$. NDNot determined. 
Table of Contents Graphic

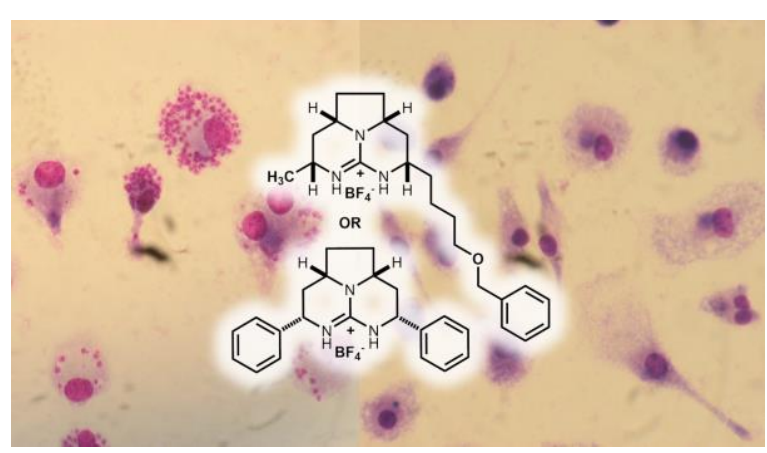

